\title{
Instrumentação aplicada em máquinas agrícolas: revisão sistemática da literatura
}

\author{
Instrumentation applied in agricultural machines: systematic literature review \\ Instrumentación aplicada en máquinas agrícolas: revisión sistemática de la literatura
}

Recebido: 02/12/2021 | Revisado: 07/12/2021 | Aceito: 11/12/2021 | Publicado: 20/12/2021

\author{
Thiago Santana Aranha \\ ORCID: https://orcid.org/0000-0003-3174-1330 \\ Centro Universitário Católico Salesiano Auxilium, Brasil \\ E-mail: thiagosantana@unisalesiano.com.br \\ Mario Mollo Neto \\ ORCID: https://orcid.org/0000-0002-8341-4190 \\ Universidade Estadual Paulista, Brasil \\ E-mail: mario.mollo@unesp.br \\ Mariana Matulovic da Silva Rodrigueiro \\ ORCID: https://orcid.org/0000-0001-6626-4621 \\ Universidade Estadual Paulista, Brasil \\ E-mail: mariana.matulovic@unesp.br \\ Flávio José de Oliveira Morais \\ ORCID: https://orcid.org/0000-0002-7638-1984 \\ Universidade Estadual Paulista, Brasil \\ E-mail: flavio.morais@unesp.br \\ Paulo Sérgio Barbosa dos Santos \\ ORCID: https://orcid.org/0000-0001-8211-3882 \\ Universidade Estadual Paulista, Brasil \\ E-mail: paulo.sb.santos@unesp.br
}

\begin{abstract}
Resumo
Afim de analisar as publicações acerca da utilização da instrumentação na agricultura, o objetivo deste trabalho é apresentar um conjunto de trabalhos publicados entres os anos de 2017 e 2021 sobre o tema para que se possa realizar uma análise das tecnologias desenvolvidas neste período. Para isso foi realizada uma busca nas bases de dados IEEE, Science Direct e Scopus onde, a partir de String de busca para selecionar trabalhos considerando tema, ano de publicação, foram encontrados 1490 artigos publicados. Diante deste resultado foi utilizado o software Start para aplicar critérios de seleção para escolha dos artigos a ser utilizados na revisão. Depois de executadas todas as etapas de seleção dos trabalhos no software o resultado foram 33 artigos realização da Revisão Sistemática. Dos 33 artigos são apresentados os métodos de trabalho e o resultado obtido pelo autor e assim possibilitando uma análise das tecnologias pesquisadas ao logo do período de estudo.
\end{abstract}

Palavras-chave: Agricultura; Agricultura de precisão; Instrumentação agrícola; Máquinas agrícolas.

\begin{abstract}
In order to analyze the publications on the use of instrumentation in agriculture, the objective of this paper is to present a set of works published between 2017 and 2021 on the subject so that an analysis of the technologies developed during this period can be carried out. For this, a search was carried out in the IEEE, Science Direct and Scopus databases, where 1490 published articles were found using a search string to select papers considering theme, year of publication. In view of this result, the Start software was used to apply selection criteria to choose the articles to be used in the review. After performing all the steps of selection of works in the software, the result was 33 papers carrying out the Systematic Review. Of the 33 articles, the work methods and the result obtained by the author are presented, thus enabling an analysis of the technologies researched during the study period.
\end{abstract}

Keywords: Agriculture; Precision agriculture; Agricultural instrumentation; Agricultural machinery.

\section{Resumen}

Para analizar las publicaciones sobre el uso de la instrumentación en la agricultura, el objetivo de este trabajo es presentar un conjunto de trabajos publicados entre 2017 y 2021 sobre el tema para que se pueda realizar un análisis de las tecnologías desarrolladas durante este período. Para ello, se realizó una búsqueda en las bases de datos IEEE, Science Direct y Scopus, donde se encontraron 1490 artículos publicados utilizando una cadena de búsqueda para seleccionar artículos considerando tema, año de publicación. Ante este resultado, se utilizó el software Start para aplicar criterios de selección para elegir los artículos a utilizar en la revisión. Después de realizar todos los pasos de selección de trabajos en el software, el resultado fue 33 artículos realizando la Revisión Sistemática. De los 33 artículos, se presentan los 
métodos de trabajo y el resultado obtenido por el autor, lo que permite un análisis de las tecnologías investigadas durante el período de estudio.

Palabras clave: Agricultura; Agricultura de precisión; Instrumentación agrícola; Máquinas agrícolas.

\section{Introdução}

O mundo passa pela crescente demanda de água, energia e alimentos, os dados de produção agrícola do Brasil determinam a grande relevância no cenário mundial como importante produtor de alimentos, contudo a produção agrícola em larga escala demanda alguns cuidados, principalmente com relação às questões ambientais, tendo em vista que o Brasil possui grandes áreas de vegetação a serem preservadas, sendo assim torna-se desafiador o aumento da produção sem que seja necessário aumentar as áreas plantadas, por este motivo, para que se tenha esse ganho de produtividade o desenvolvimento e utilização de tecnologias na produção agrícola tornou-se essencial.

Diante disso, tornou-se inevitável a automação de processos da produção agrícola, assim com a utilização das máquinas para ampliar a capacidade humana na realização de determinadas tarefas modificou a capacidade de realizar trabalhos e também a dimensão das lavouras. A utilização das máquinas possibilitou maior uniformidade e a busca constante por menos perdas e maior eficiência na produção, assim a qualidade e eficiência passou a ser perseguida pelos agricultores e desenvolvedores de equipamentos.

Evidentemente o processo de evolução tecnológico se deu por muitos anos de pesquisa e desenvolvimento, dessa forma justifica-se a realização de uma Revisão Sistemática da literatura afim de verificar os trabalhos realizados acerca do tema, este estudo faz uma análise dos trabalhos publicados dos anos de 2017 a 2021 nas bases de dados IEEE, Science Direct e Scopus para assim determinar como se deu esse processo de evolução nos últimos 5 anos e perspectivas futuras.

Um ponto importante a se tratar é com relação ao estudo e desenvolvimento de novas tecnologias, esses estudos promovem a maior acessibilidade às tecnologias antes empregadas apenas à produção em larga escala e também possibilita implantação até mesmo na agricultura familiar devido a redução do custo de implantação conforme avançam os estudos. A importância do desenvolvimento tecnológico na agricultura faz relação inclusive ao pacto global da ONU (Organização das Nações Unidas) e as ODS (Objetivos do Desenvolvimento Sustentável no Brasil). Esta relação pode ser enquadrada inclusive no objetivo 2 pois busca a promoção de agricultura sustentável e o objetivo 8 com foco em promover às comunidades agrícolas crescimento econômico inclusivo e sustentável (ONU, 2021).

\section{Metodologia}

Diante da importância da instrumentação nos equipamentos utilizados nos processos mecanizados na agricultura, fazse importante analisar trabalhos realizados acerca do tema para que se possa investigar tanto a contribuição para avanço tecnológico quanto as perspectivas futuras de desenvolvimento. Para este estudo torna-se importante a realização de Revisão Sistemática da Literatura (RSL) acerca do tema para assim obter os resultados propostos.

Revisão Sistemática da Literatura é um método de estudo que aplica estratégias para, a partir de base de dados de arquivos relacionados ao tema, selecionar, analisar, avaliar e sintetizar os trabalhos para que se tenha um estudo consistente do tema e assim até mesmo definir direções para pesquisas futuras.

Para a realização desta RSL primeiramente realizou-se busca nas bases de dados IEEE Xplore, Science Direct e Scopus todos os trabalhos publicados a partir do ano de 2017 onde os resultados dessa busca está no Gráfico 1. 
Gráfico 1 - Trabalhos publicados nos últimos 5 anos nas bases de dados.

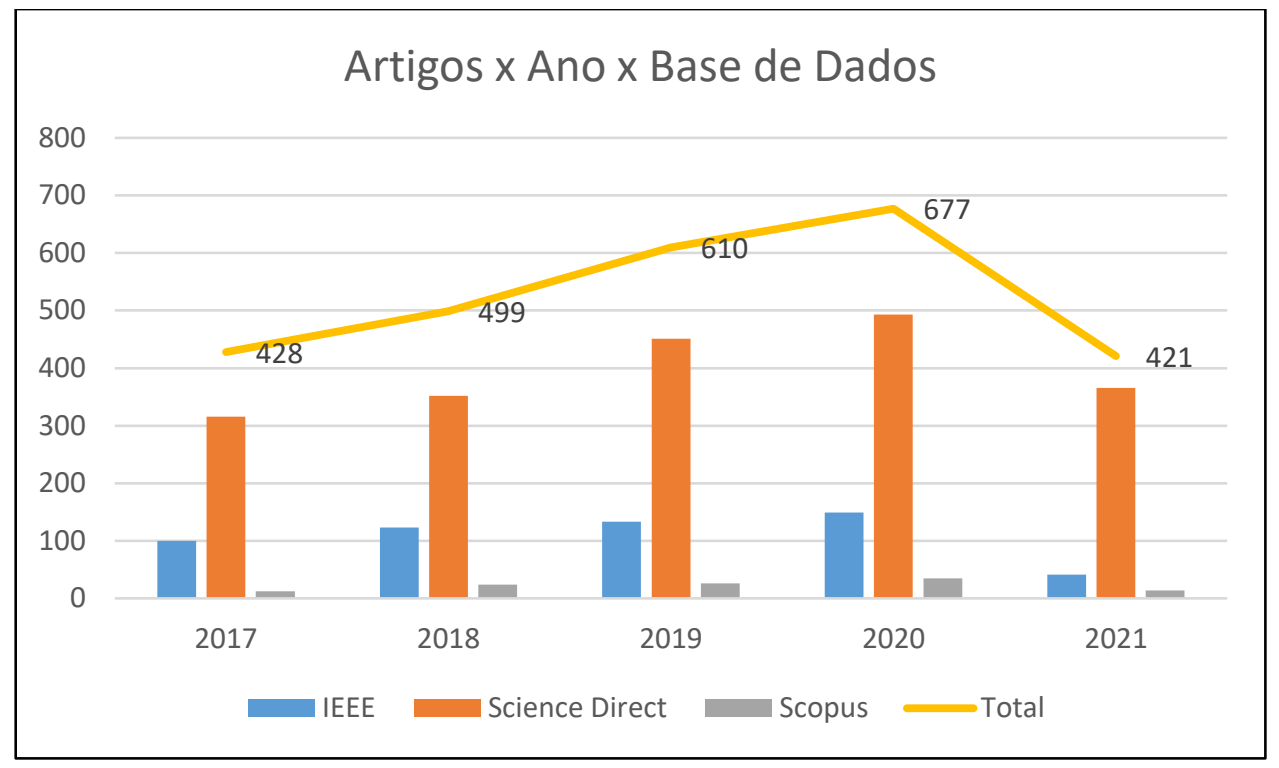

Fonte: Autores (2021).

No Gráfico 1 além de mostrar a quantidade de trabalhos publicados, também é possível visualizar como a quantidade de trabalhos realizados se desenvolveu de forma crescente nos últimos anos.

A partir dos dados foi realizado os processos de análise dos trabalhos, este processo de análise de desenvolveu em três etapas: entrada, processamento e saída. Para a concretização das etapas foi utilizado o software StArt (State of the Art through Systematic Review) que é um software gratuito, que foi desenvolvido no Laboratório de Pesquisa em Engenharia de Software da UfScar. O software StArt divide o estudo em três fases: protocolo, execução e sumarização e após completadas todas as fases tem-se os arquivos selecionados para continuidade da RSL.

No protocolo são estabelecidos os critérios de seleção dos arquivos, nessa etapa são definidos os objetivos e os critérios de inclusão ou exclusão de arquivos para o estudo, é nessa etapa que são selecionadas as bases de dados para a pesquisa.

Dentre as palavras-chaves utilizadas para seleção dos trabalhos, a Figura 1 apresenta a nuvem de palavras ilustrando sua frequência nos trabalhos.

Figura 1 - Nuvem de palavras no Abstract.

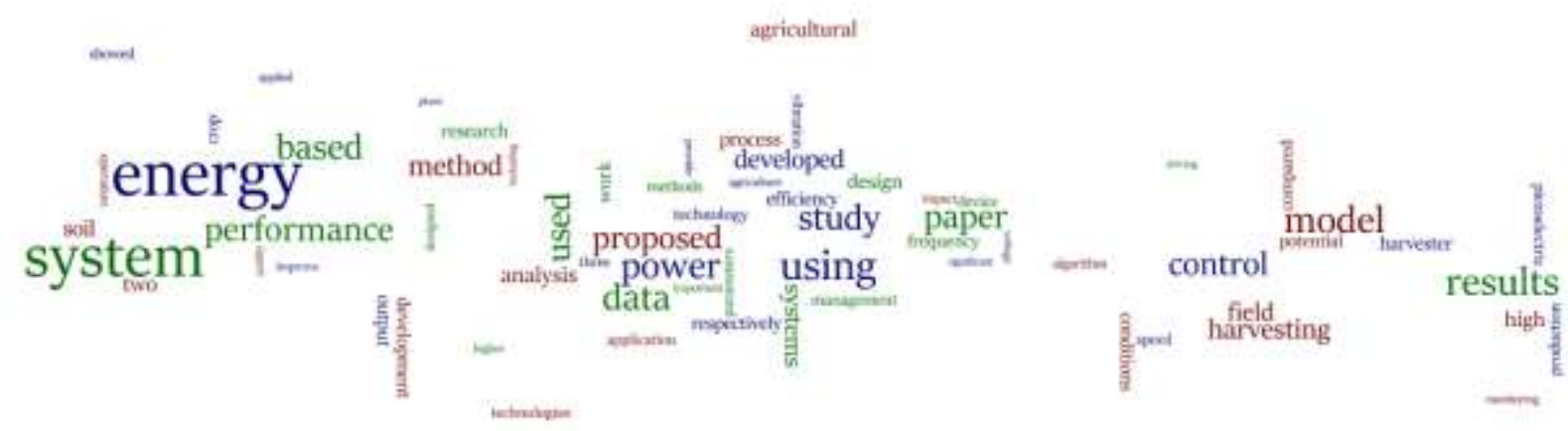

Fonte: Autores (2021).

Na execução os dados dos arquivos das bases de dados são adicionados e a partir das informações inseridas no protocolo como palavras-chave, o software analisa e pontua os trabalhos permitindo uma classificação por pontuação e assim já estabelecendo os trabalhos de interesse, nessa fase o software também identifica trabalhos duplicados e assim possibilita definir 
os trabalhos aceitos para realização da RSL.

A sumarização mostra os resultados em forma de gráficos os resultados obtidos nas etapas anteriores.

\subsection{Entrada}

Nesta fase inicial, foi definido qual o objetivo da pesquisa, os problemas a serem resolvidos, as bases de dados que seriam utilizadas, as strings de busca para encontrar artigos que realmente estivessem de acordo com o tema a ser pesquisado e os critérios de inclusão e exclusão dos trabalhos. O Quadro 1 apresenta os parâmetros de entrada da RSL.

Quadro 1 - Parâmetros de entrada da RBS.

Objetivo
Apresentar a importância da instrumentação na agricultura e automação das máquinas agrícolas para melhor
eficiência na produção em larga escala base em artigos acadêmicos sobre o tema nos anos entre 2017 e 2021.
Situação problema
A automação de processos causa impactos na produção agrícola?
Bases de Dados
IEEE, Scopus, Science Direct
$\quad$ String de busca
(automation OR instrumentation) AND (“agricultural machinery” OR “agricultural machine” OR harvester OR
tractor OR planter OR “agricultural implement”)
Palavras-Chave
Agricultural, Agricultural Machinery, Agricultural Robotics, Agricultural automation, Agricultural robot,
Agricultural robots, Agriculture, Automation, Control System, Machine, Mechanization, Robotics, Robots,
Sensor, Sensors, Smart Agriculture, Tractor.
Critérios de inclusão dos artigos nas bases de dados
Inclusão (I) - Estudo de processos automatizados na agricultura
Inclusão (I) - Trabalhos publicados a partir do ano de 2017
Inclusão (I) - Utilização de instrumentação eletrônica na produção Agrícola
Critérios de exclusão dos artigos nas bases de dados
Exclusão (E) - Outros processos de produção que não seja a produção agrícola
Exclusão (E) - Artigos publicados a mais de 5 anos
Exclusão (E) - Trabalho que não apresentar Resumo/Abstract

Fonte: Autores (2021).

Dessa forma, devido definição dos parâmetros de entrada para a execução da RBS, passou-se para a etapa de processamento, com busca nas bases de dados e análise das publicações.

\subsection{Processamento}

O software, a partir dos arquivos das bases de dados e os critérios de seleção dos trabalhos, foram selecionados os trabalhos para avaliação onde esse resultado é mostrado no Gráfico 1.

Na figura 2 é possível visualizar que dos 1490 artigos encontrados nas bases de dados, pelos critérios de seleção, 1424 trabalhos foram rejeitados, 4 trabalhos duplicados e 62 trabalhos selecionados para avaliação. 
Figura 2 - Fluxograma do processo de seleção dos Artigos.

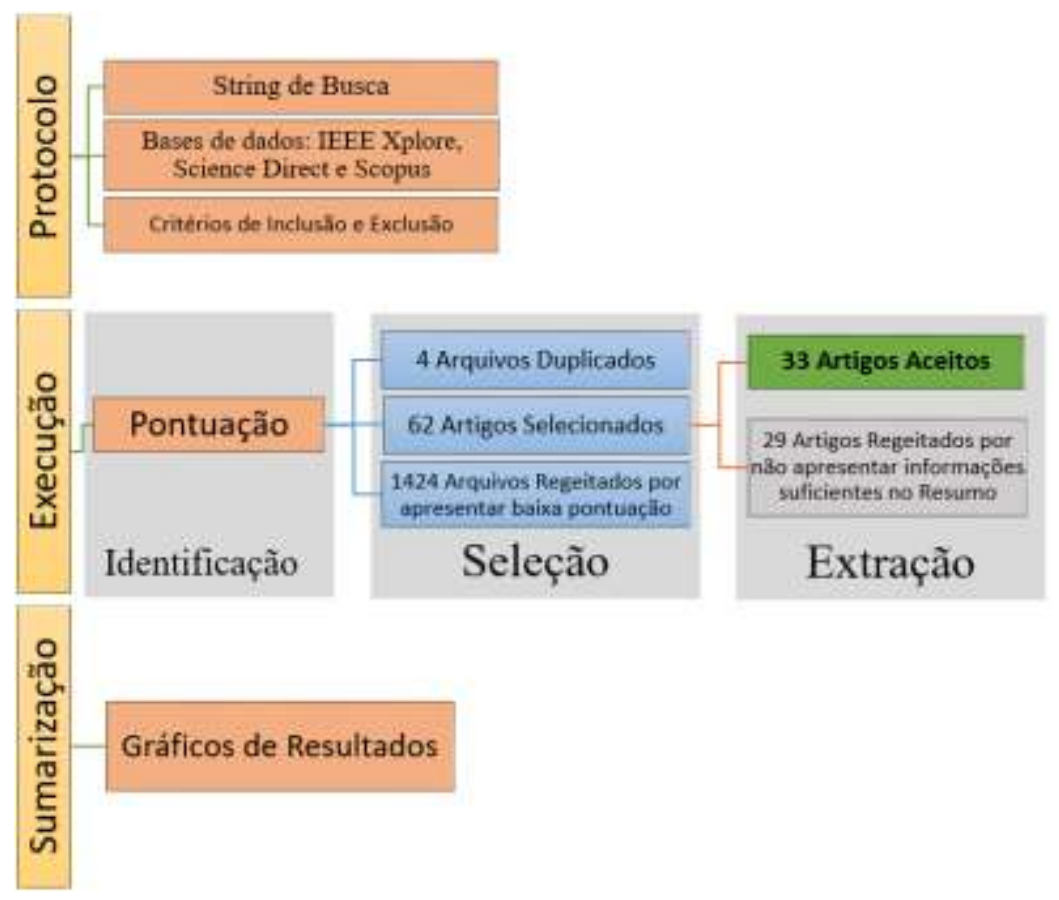

Fonte: Autores (2021).

Dos trabalhos selecionados para análise, após verificação dos resumos dos trabalhos, seguindo o critério que o resumo apresente estudo, desenvolvimento e resultado, depois de analisados todos os trabalhos, foram selecionados os trabalhos para realização da RSL conforme gráfico 3. Nota-se que dos 62 trabalhos selecionado para análise, 33 trabalhos foram aceitos para realização da RSL e 29 recusados devido resumo não conter dados suficientes para inclusão na pesquisa.

\section{Resultados e Discussão}

Após realizado o processamento dos dados, a partir dos critérios estabelecidos de inclusão e exclusão de trabalhos, foram selecionados 33 trabalhos para a realização da RBS. A figura 3 representa a nuvem de palavras relacionadas nas palavraschave dos trabalhos selecionados.

Figura 3 - Nuvem de palavras-chave.

Precision-agriculture

Agriculture

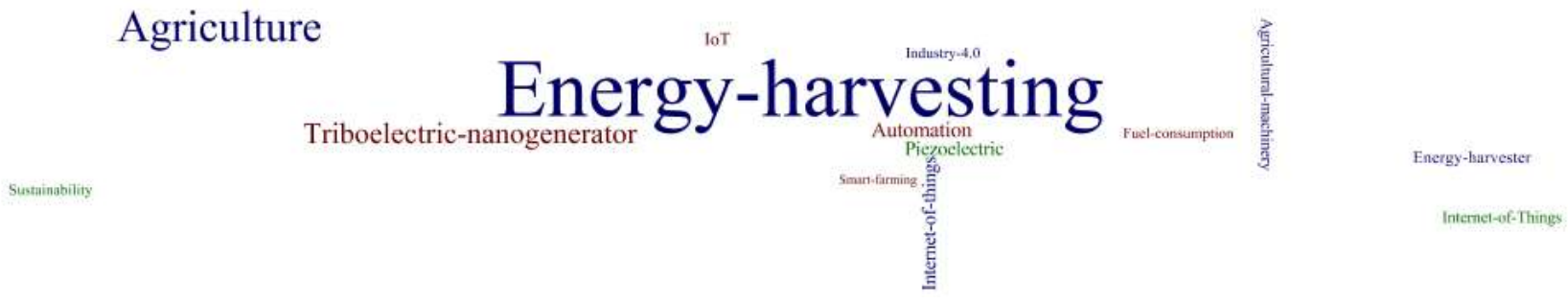

Fonte: Autores (2021).

Nota-se a frequente utilização da palavra Energy-harvesting evidenciando o esforço dos pesquisadores no desenvolvimento de tecnologias para melhor aproveitamento da energia nos processos da agricultura, nota-se também frequência nas palavras Precision-agriculture, Automation e Agricultural-machinery, dessa forma mostra-se importante o estudo de tecnologias na agricultura. 
Research, Society and Development, v. 10, n. 17, e22101724247, 2021

(CC BY 4.0) | ISSN 2525-3409 | DOI: http://dx.doi.org/10.33448/rsd-v10i17.24247

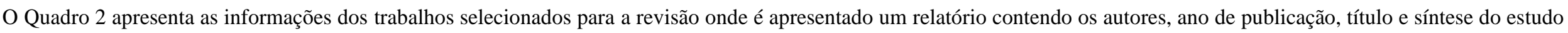
dos autores, bem como método e resultados obtidos estudo por estudo para que se possa realizar análise acerca dos estudos realizados do tema.

Quadro 2 - Artigos Selecionados para revisão sistemática da literatura

\begin{tabular}{|c|c|c|c|c|c|}
\hline Título & Ano & Autores & Objetivo & Metodologia & Resultados \\
\hline $\begin{array}{l}\text { Damage Evaluation } \\
\text { Of Driving Events } \\
\text { For Agricultural } \\
\text { Tractors }\end{array}$ & 2017 & $\begin{array}{c}\text { MATTETTI, M. et } \\
\text { al }\end{array}$ & $\begin{array}{l}\text { Desenvolvimento de uma metodologia } \\
\text { de processamento de sinal para } \\
\text { identificar automaticamente os eventos } \\
\text { de alto dano para carcaças de eixo. }\end{array}$ & $\begin{array}{l}\text { Um trator agrícola foi equipado com quatro Transdutores de Força de } \\
\text { Roda (WFTs) e um registrador de dados baseado em CAN-Bus para } \\
\text { adquirir as cargas da carcaça do eixo e os sinais de operação do } \\
\text { motorista. Foram adquiridos sinais para três aplicações distintas como } \\
\text { aração, subsolagem e transporte de implementos. Os eventos de } \\
\text { carregamento foram identificados através da análise do Coeficiente de } \\
\text { Correlação Time-Varying par a par (TVCC) entre os sinais de operação } \\
\text { do driver e os sinais WFT. Um evento de direção foi classificado como } \\
\text { um padrão de TVCCs e, para cada um, foi calculado o Pseudo-Dano } \\
\text { Variável no Tempo (TVPD). }\end{array}$ & $\begin{array}{l}\text { Usando esta metodologia, verificou-se que o evento mais } \\
\text { prejudicial para as carcaças dos eixos ocorre durante a curva do cabo } \\
\text { devido às aceleraçôes de carga total e transferência de carga vertical } \\
\text { entre os eixos dianteiro e traseiro. Por essas razões, as operações em } \\
\text { campo eram mais prejudiciais do que o transporte off-road. }\end{array}$ \\
\hline $\begin{array}{l}\text { Performance Of } \\
\text { Tractor And Tillage } \\
\text { Implements In Clay } \\
\quad \text { Soil }\end{array}$ & 2017 & $\begin{array}{l}\text { RANJBARIAN, S.; } \\
\text { ASKARI, M.; } \\
\text { JANNATKHAH, J. }\end{array}$ & $\begin{array}{l}\text { Desenvolvimento de um sistema de } \\
\text { instrumentação móvel montado em um } \\
\text { trator MF } 285 \text { para medir os parâmetros } \\
\text { de desempenho do trator e implementos } \\
\text { acoplados. O sistema mede o ruído, o } \\
\text { consumo de combustível, a velocidade } \\
\text { real de avanço, a profundidade do } \\
\text { preparo do solo e a velocidade do motor. }\end{array}$ & $\begin{array}{l}\text { Os parâmetros, como patinagem das rodas, força da barra de tração e } \\
\text { eficiência de tração seriam calculados pelo padrão ASABE. Foram } \\
\text { examinados três implementos incluídos de arado de aiveca, arado de } \\
\text { disco e escarificador em quatro velocidades de avanço }(1.5,2.3,3 \text { e } \\
4 \mathrm{~km} / \mathrm{h} \text { ) em profundidade de } 23 \mathrm{~cm} \text { e rotação do motor de } 1500 \mathrm{rpm}\end{array}$ & $\begin{array}{l}\text { A análise de variância (ANOVA) dos dados resultantes revelou que } \\
\text { o aumento da velocidade de avanço resulta em aumento do calado } \\
\text { do implemento, derrapagem da roda, força da barra de tração e } \\
\text { eficiência energética geral, mas resulta em diminuiçãa da eficiência } \\
\text { de tração. Além disso, o consumo de combustível diminuiu com o } \\
\text { aumento da velocidade de } 1,5 \mathrm{~km} / \mathrm{h} \text { para } 3 \mathrm{~km} / \mathrm{h} \text {, mas aumentou com } \\
\text { o aumento da velocidade de } 3 \mathrm{~km} / \mathrm{h} \text { para } 4 \mathrm{~km} / \mathrm{h} \text {. Observou-se } \\
\text { também que a exigência de calado para implementos em testes } \\
\text { variou de } 8,2 \mathrm{kN} \text { para o arado de disco a } 13 \mathrm{kN} \text { para o escarificador } \\
\text { e o consumo de combustível variou de } 10,72 \mathrm{~L} / \mathrm{ha} \text { para o } \\
\text { escarificador a } 26,5 \mathrm{~L} / \mathrm{h} \text { a para o arado. }\end{array}$ \\
\hline $\begin{array}{l}\text { Computational Deep } \\
\text { Intelligence Vision } \\
\text { Sensing For Nutrient } \\
\text { Content Estimation } \\
\text { In Agricultural } \\
\text { Automation } \\
\end{array}$ & 2017 & $\begin{array}{l}\text { SULISTYO, S.B.; } \\
\text { WU, D.; WOO, } \\
\text { W.L.; DLAY, S.S.; } \\
\quad \text { GAO, B. }\end{array}$ & $\begin{array}{l}\text { Apresentar uma nova abordagem de } \\
\text { detecção de visão de inteligência } \\
\text { computacional para estimar o conteúdo } \\
\text { de nutrientes em folhas de trigo, } \\
\text { analisando características de cor das } \\
\text { imagens de folhas capturadas em campo } \\
\text { com várias condições de iluminação. }\end{array}$ & $\begin{array}{l}\text { Desenvolvimento de máquinas de aprendizado extremo esparso } \\
\text { profundo (DSELM) e algoritmo genético (GA) para normalizar imagens } \\
\text { de plantas, bem como para reduzir a variabilidade de cores devido a uma } \\
\text { variação de intensidades de luz solar. }\end{array}$ & $\begin{array}{l}\text { Os resultados mostraram a superioridade do método proposto em } \\
\text { termos de qualidade e velocidade de processamento em todas as } \\
\text { etapas, ou seja, normalização de cores, segmentação de imagens e } \\
\text { previsão de nutrientes, em comparação com outros métodos } \\
\text { existentes. }\end{array}$ \\
\hline $\begin{array}{c}\text { Embedded Digital } \\
\text { Drive Wheel Torque } \\
\text { Indicator For } \\
\text { Agricultural 2WD } \\
\text { Tractors } \\
\end{array}$ & 2017 & $\begin{array}{l}\text { KUMAR, A. A.; } \\
\text { TEWARI, V.K.; } \\
\text { NARE, B.; } \\
\text { CHETAN, C.R.; } \\
\text { SRIVASTAVA, P.; } \\
\text { KUMAR, S. P. }\end{array}$ & $\begin{array}{l}\text { Desenvolvimento de um sistema } \\
\text { embarcado baseado em microcontrolador } \\
\text { para medir e exibir o torque dinâmico do } \\
\text { eixo da roda e a força da barra de tração } \\
\text { de um trator agrícola para pesquisa de } \\
\text { cultivo. }\end{array}$ & $\begin{array}{l}\text { O dispositivo inclui um transdutor especial para medir o torque } \\
\text { dinâmico da roda motriz do trator, um sistema digital sem fio embutido } \\
\text { para receber os dados do processo e exibir digitalmente, bem como } \\
\text { gravar no módulo de cartão SD próximo ao painel do trator }\end{array}$ & $\begin{array}{l}\text { O sistema desenvolvido foi rigorosamente testado em laboratório e } \\
\text { em condições reais de campo. Verificou-se que existe uma variação } \\
\text { máxima de } \pm 320 \mathrm{Nm} \text { de torque entre os valores teoricamente } \\
\text { calculados e os experimentalmente observados em condições de } \\
\text { campo. }\end{array}$ \\
\hline $\begin{array}{l}\text { Self-Powered, } \\
\text { Autonomous } \\
\text { Biological Oxygen } \\
\text { Demand Biosensor }\end{array}$ & 2017 & $\begin{array}{l}\text { PASTERNAK, G.; } \\
\text { GREENMAN, J.; } \\
\text { IEROPOULOS, I }\end{array}$ & $\begin{array}{l}\text { Desenvolver um biossensor flutuante } \\
\text { com alimentação própria para } \\
\text { monitoramento online da qualidade da } \\
\text { água. }\end{array}$ & $\begin{array}{l}\text { A energia necessária para operar o biossensor é produzida pelo próprio } \\
\text { sistema com o uso de microrganismos eletroativos, dentro de células a } \\
\text { combustível microbianas. A Demanda Química de Oxigênio (COD) é } \\
\text { utilizada como um método rápido de validação de biossensores. Quando } \\
\text { a concentração de urina excedeu o limite inferior, correspondendo a uma }\end{array}$ & $\begin{array}{l}\text { O menor tempo de atuação observado, necessário para ligar o } \\
\text { alarme, foi de } 61 \text { minutos, quando a concentração de urina era de } \\
149,7 \pm 1,7 \mathrm{mgO} 2 \mathrm{~L}-1 \text {. Essa abordagem permitiu correlacionar e } \\
\text { detectar quantitativamente a presença de contaminação da água, }\end{array}$ \\
\hline
\end{tabular}


Research, Society and Development, v. 10, n. 17, e22101724247, 2021

(CC BY 4.0) | ISSN 2525-3409 | DOI: http://dx.doi.org/10.33448/rsd-v10i17.24247

\begin{tabular}{|c|c|c|c|c|c|}
\hline $\begin{array}{l}\text { For Online Water } \\
\text { Quality Monitoring }\end{array}$ & & & & $\begin{array}{l}\text { concentração de COD de } 57,7 \pm 4,8 \mathrm{mgO} 2 \mathrm{~L}-1 \text {, o biossensor ligou o } \\
\text { alarme. }\end{array}$ & $\begin{array}{l}\text { com base na frequência do sinal. O sensor operou de forma } \\
\text { autônoma por } 5 \text { meses. }\end{array}$ \\
\hline $\begin{array}{c}\text { Mixtures of } \\
\text { Lightweight Deep } \\
\text { Convolutional Neural } \\
\text { Networks: Applied to } \\
\text { Agricultural } \\
\text { Robotics } \\
\end{array}$ & 2017 & $\begin{array}{l}\text { MCCOOL C.S.; } \\
\text { PEREZ, T.; } \\
\text { UPCROFT, B. }\end{array}$ & $\begin{array}{l}\text { Proposta de uma nova abordagem para o } \\
\text { treinamento de redes neurais } \\
\text { convolucionais profundas (DCNNs) }\end{array}$ & $\begin{array}{l}\text { Compensar complexidade e precisão para aprender modelos leves } \\
\text { adequados para plataformas robóticas, como AgBot II (que executa o } \\
\text { gerenciamento automatizado de ervas daninhas) }\end{array}$ & $\begin{array}{l}\text { Aplicado à tarefa desafiadora de segmentação de ervas daninhas, a } \\
\text { precisão melhorou de } 85,9 \% \text {, usando uma abordagem tradicional, } \\
\text { para } 93,9 \% \text {, adaptando um DCNN pré-treinado complicado com } \\
\text { parâmetros de } 25 \mathrm{M} \text { (Inception-v3). }\end{array}$ \\
\hline $\begin{array}{c}\text { Design And } \\
\text { Experiment Of } \\
\text { Remote Intelligent } \\
\text { Spray Control } \\
\text { System Based On } \\
\text { Embedded Internet } \\
\end{array}$ & 2018 & $\begin{array}{l}\text { YALEI, W.; LIJUN, } \\
\text { Q.; HAO, Z. }\end{array}$ & $\begin{array}{l}\text { Proposta de uma tecnologia embarcada, } \\
\text { que utilize os micro controladores } \\
\text { STM32F101 e STM32F103 como núcleo } \\
\text { e base, combinado com } 4 \mathrm{G} \text { Internet e } \\
\text { algoritmo de detecção ultrassônica de } \\
\text { alvos para pulverização. }\end{array}$ & $\begin{array}{l}\text { O sistema usou Socket e tecnologia multi-thread para implementar } \\
\text { comunicação bidirecional no ambiente de desenvolvimento Eclipse e } \\
\text { Keil-uvision4. Com o protocolo de comunicação TCP como meio, o } \\
\text { Android e o cliente transferiram o roteamento remoto pela Internet ou } \\
\text { placa de rede sem fio para obter o controle remoto inteligente. O sistema } \\
\text { pode realizar a aplicação precisa de pesticidas. }\end{array}$ & $\begin{array}{l}\text { Por meio de testes, pode-se constatar que a detecção e o } \\
\text { processamento das falhas na fuselagem possuem alta confiabilidade. } \\
\text { Ao mesmo tempo, tem valor potencial de aplicação para a } \\
\text { transformação dos modos de produção tradicionais e a promoção de } \\
\text { máquinas agrícolas inteligentes. }\end{array}$ \\
\hline $\begin{array}{l}\text { Predictive Analysis } \\
\text { Of Crops Cultivation } \\
\text { For A Smart Green } \\
\text { Environment Using } \\
\quad \text { Azure Services } \\
\end{array}$ & 2018 & $\begin{array}{l}\text { RAJKUMAR, S.; } \\
\text { ARUN M.; } \\
\text { HIRWANI, J.; } \\
\text { SANJEEV, SS. }\end{array}$ & $\begin{array}{l}\text { Coletar dados de sensores em tempo real } \\
\text { de um ambiente verde e fazer previsões } \\
\text { sobre o padrão de cultivo das safras com } \\
\text { base nas condições climáticas por meio } \\
\text { dos serviços MS Azure IFTTT. Â } \odot \\
\text { BEIESP. }\end{array}$ & $\begin{array}{l}\text { Implementar um sistema prático que trata do monitoramento do campo } \\
\text { de cultivo através de uma rede sem fio de sensores (luz, umidade, } \\
\text { temperatura, umidade do solo, indicador de nível de água etc.) e } \\
\text { automatiza o sistema de irrigação com base nas diversas restrições do } \\
\text { campo. }\end{array}$ & $\begin{array}{l}\text { Os agricultores podem monitorar as condições da fazenda por meio } \\
\text { de um aplicativo web de qualquer lugar, a qualquer hora e receber } \\
\text { notificações oportunas sobre as mudanças na fazenda. Isso torna a } \\
\text { agricultura baseada em IoT altamente eficiente quando comparada } \\
\text { com a abordagem de cultivo convencional }\end{array}$ \\
\hline $\begin{array}{l}\text { Adaptation Of Tilt } \\
\text { Adjustment And } \\
\text { Tracking Force } \\
\text { Automation System } \\
\text { On A Laser- } \\
\text { Controlled Land } \\
\text { Leveling Machine } \\
\end{array}$ & 2018 & $\begin{array}{l}\text { İRSEL, Gürkan M.; } \\
\text { ALTINBALIK, } \\
\text { Tahir. }\end{array}$ & $\begin{array}{l}\text { Melhorar a eficiência operacional das } \\
\text { máquinas de nivelamento a laser e } \\
\text { projetar um sistema mais preciso, } \\
\text { ergonômico, econômico e confiável. }\end{array}$ & $\begin{array}{l}\text { Um sistema de automação de ajuste de inclinação da lâmina, sistema de } \\
\text { automação de esteira e sistema de proteção de carga máxima. }\end{array}$ & $\begin{array}{l}\text { Com seu novo design, a máquina pode nivelar terrenos mais difíceis } \\
\text { por menos número de repetições e menos consumo de combustível } \\
\text { com uma precisão de gradiente de } 0,05 \text { ○. Após o projeto, a } \\
\text { economia de tempo de } 80 \% \text { e a economia de combustível de } 85 \% \\
\text { foram alcançadas para as superfícies com a mesma área e } \\
\text { aproximadamente } 10 \text { litros de economia de combustível por acre foi } \\
\text { realizada. }\end{array}$ \\
\hline $\begin{array}{c}\text { Road Bump } \\
\text { Detection Using } \\
\text { Lidar Sensor For } \\
\text { Semi-Active Control } \\
\text { Of Front Axle } \\
\text { Suspension In An } \\
\text { Agricultural Tractor }\end{array}$ & 2018 & $\begin{array}{l}\text { LEE, Jung-Hwan; } \\
\text { KIM, Hak-Jin; } \\
\text { CHO, Bong-Jin; } \\
\text { CHOI, Jin-Ha; KIM, } \\
\text { Young-Joo. }\end{array}$ & $\begin{array}{l}\text { Desenvolvimento de um método que } \\
\text { detecta obstáculos na superfície da } \\
\text { estrada usando um sensor LiDAR para } \\
\text { prever uma mudança na condição do solo } \\
\text { com antecedência }\end{array}$ & $\begin{array}{l}\text { A rugosidade da superfície da estrada foi quantificada comparando a } \\
\text { diferença do valor médio das distâncias entre cada um dos locais } \\
\text { medidos com o sensor LiDAR na região de interesse. O uso do sensor } \\
\text { LiDAR montado na frente do trator permitiu que tanto a condição de } \\
\text { rugosidade da superfície da estrada quanto a presença de solavancos } \\
\text { fossem detectados em uma faixa típica de velocidades de deslocamento } \\
\text { de tratores ao usar valores limite adequados para distinguir entre um } \\
\text { solavanco e outros objetos. }\end{array}$ & $\begin{array}{l}\text { Os resultados dos testes de campo mostraram que a aceleração } \\
\text { vertical da carroceria do veículo foi reduzida em } 54 \% \text {, ao passar pela } \\
\text { lombada a } 5 \mathrm{~km} / \mathrm{h} \text { e o deslocamento do eixo foi reduzido em } 51 \% \\
\text { ao percorrer uma estrada regular a } 5 \mathrm{~km} / \mathrm{h} \text {, em comparação com } \\
\text { aquelas obtido com o trator sem o sistema de detecção de solavancos }\end{array}$ \\
\hline $\begin{array}{c}\text { Development Of } \\
\text { Automation } \\
\text { Technology For } \\
\text { Manual } \\
\text { Transmission Of A } \\
\text { 50 HP Autonomous } \\
\text { Tractor } \\
\end{array}$ & 2018 & $\begin{array}{l}\text { KIM, Yong-Joo; } \\
\text { CHUNG, Sun-Ok; } \\
\text { CHOI, C.H. }\end{array}$ & $\begin{array}{l}\text { Desenvolver tecnologia de automação } \\
\text { para transmissão manual de um trator } \\
\text { autônomo de } 50 \mathrm{HP}\end{array}$ & $\begin{array}{l}\text { Atuadores elétricos foram desenvolvidos para a troca automática de } \\
\text { marchas e controle de embreagem. }\end{array}$ & $\begin{array}{l}\text { O resultado mostrou que a duração total máxima e o choque de } \\
\text { deslocamento de todas as direções de deslocamento foram menores } \\
\text { que } 2,5 \text { seg e } 0,55 \mathrm{G} \text {. Os resultados mostraram que os atuadores } \\
\text { desenvolvidos com algoritmo de controle de deslocamento podem } \\
\text { ser úteis para a automação da transmissão manual de um trator } \\
\text { agrícola de } 50 \mathrm{HP} \text {. }\end{array}$ \\
\hline $\begin{array}{l}\text { Development Of A } \\
\text { Prediction Model For } \\
\text { Estimating Tractor } \\
\text { Engine Torque Based } \\
\text { On Soft Computing }\end{array}$ & 2018 & $\begin{array}{l}\text { RAJABI- } \\
\text { Vandechali, Majid; } \\
\text { ABBASPOUR- } \\
\text { Fard, Mohammad; } \\
\text { ROHANI, Abbas. }\end{array}$ & $\begin{array}{l}\text { Proposta de um modelo baseado em soft } \\
\text { computing para estimar o torque do } \\
\text { motor do trator ITM } 285 \text { usando alguns } \\
\text { sensores de baixo custo. }\end{array}$ & $\begin{array}{l}\text { Foram utilizados dois modelos incluindo a rede neural de função de base } \\
\text { radial (RBF) o o sistema de inferência neuro difuso adaptativo (ANFIS). } \\
\text { Treze algoritmos de treinamento foram examinados para treinar o RBF. } \\
\text { Esses algoritmos foram comparados usando três métodos estatísticos, ou } \\
\text { seja, validação cruzada k-fold, design completamente aleatório (CRD) e }\end{array}$ & $\begin{array}{l}\text { A análise de sensibilidade mostrou que apenas medir a velocidade } \\
\text { do motor, fluxo de massa de combustível e temperatura dos gases } \\
\text { de escape foi suficiente para a estimativa adequada do torque do } \\
\text { motor. }\end{array}$ \\
\hline
\end{tabular}




\begin{tabular}{|c|c|c|c|c|c|}
\hline $\begin{array}{l}\text { And Low Cost } \\
\text { Sensors }\end{array}$ & & & & $\begin{array}{l}\text { diferença mínima significativa (LSD). Além disso, três métodos, } \\
\text { particionamento de grade (GP), subcluster (SC) e fuzzy c-means (FCM), } \\
\text { foram usados para construir o sistema de inferência fuzzy (FIS). }\end{array}$ & \\
\hline $\begin{array}{l}\text { Tractor Path } \\
\text { Tracking Control } \\
\text { Based On Binocular } \\
\text { Vision }\end{array}$ & 2018 & $\begin{array}{l}\text { ZHANG, Shuo; } \\
\text { WANG, Yunyi; } \\
\text { ZHU, Zongshun; LI, } \\
\text { Zhen; DU, Yuefeng; } \\
\text { MAO, Enrong. }\end{array}$ & $\begin{array}{l}\text { De acordo com a operação linear no } \\
\text { processo de gerenciamento do campo de } \\
\text { algodão, projetar um sistema de controle } \\
\text { de rastreamento da trajetória do trator } \\
\text { com base na visão binocular e no modelo } \\
\text { de perseguição pura. }\end{array}$ & $\begin{array}{l}\text { Primeiro, o software de computador superior foi desenvolvido por C ++ } \\
\text { com as funçôes de configuração de parâmetros e aquisição e } \\
\text { processamento de imagem. Em segundo lugar, um controlador de } \\
\text { direção automática foi desenvolvido com base no microprocessador } \\
\text { MC9S12XS128 da Freescale. O programa de controle foi desenvolvido } \\
\text { com base no design modular usando CodeWarrior durante o } \\
\text { desenvolvimento da estratégia de controle de direção automática baseada } \\
\text { em PID }\end{array}$ & $\begin{array}{l}\text { Os resultados experimentais mostram que o método de detecção de } \\
\text { linha de cultura com base na transformação do Censo pode } \\
\text { identificar a linha de cultura e planejar bem o caminho de navegação } \\
\text { e o sistema de controle de rastreamento do caminho do trator com } \\
\text { base na visão binocular tem boa estabilidade e alta precisão de } \\
\text { controle; assim, o sistema de controle pode realizar o controle } \\
\text { automático de rastreamento do caminho da operação da linha de } \\
\text { algodão. }\end{array}$ \\
\hline $\begin{array}{l}\text { Machine Learning } \\
\text { For Automatic Rule } \\
\text { Classification Of } \\
\text { Agricultural } \\
\text { Regulations: A Case } \\
\text { Study In Spain }\end{array}$ & 2018 & $\begin{array}{l}\text { ESPEJO, Garcia B.; } \\
\text { MARTINEZ, } \\
\text { Guanter J.; PÉREZ, } \\
\text { Ruiz M.; LOPEZ, } \\
\text { Pellicer F.J.; } \\
\text { JAVIER, Zarazaga- } \\
\text { Soria F. } \\
\end{array}$ & $\begin{array}{l}\text { Avaliar empiricamente o desempenho de } \\
\text { quatro algoritmos de aprendizado de } \\
\text { máquina populares na tarefa de } \\
\text { classificar corretamente os regulamentos } \\
\text { de pesticidas como proibições ou } \\
\text { obrigações }\end{array}$ & & $\begin{array}{l}\text { Experimentos mostram que a combinação do algoritmo de } \\
\text { aprendizado de máquina Logic regression, a técnica de linguagem } \\
\text { natural de marcação de parte do discurso e a técnica de } \\
\text { reamostragem Tomek links é a abordagem de melhor desempenho, } \\
\text { com uma pontuação F1 de } 68,8 \% \text {, uma precisão de } 84,46 \% \text { e um } \\
\text { recordação de } 60 \% \text {. }\end{array}$ \\
\hline $\begin{array}{l}\text { UAV Application } \\
\text { For Precision } \\
\text { Agriculture }\end{array}$ & 2018 & $\begin{array}{l}\text { PERZ, Rafal; } \\
\text { WRONOWSKI, } \\
\text { Kacper. }\end{array}$ & $\begin{array}{l}\text { Mostrar os potenciais de um sistema de } \\
\text { veículos aéreos não tripulados (VANT) } \\
\text { de baixo custo para a indústria agrícola. }\end{array}$ & $\begin{array}{l}\text { O plano de pesquisa era integrar a plataforma e executar inúmeros voos } \\
\text { experimentais sobre fazendas, campos e bosques coletando fotos aéreas. } \\
\text { Todas as missões foram planejadas para servir às indústrias agrícolas e } \\
\text { florestais locais e cooperar com as autoridades comerciais locais. }\end{array}$ & $\begin{array}{l}\text { Obtenção de mapas de ortofoto de alta qualidade, mapas 3D, } \\
\text { modelos digitais de superfície e mosaicos de imagens com índice de } \\
\text { vegetação de diferença normalizado. }\end{array}$ \\
\hline $\begin{array}{l}\text { Development Of A } \\
\text { Following } \\
\text { Agricultural } \\
\text { Machinery } \\
\text { Automatic } \\
\text { Navigation System }\end{array}$ & 2019 & $\begin{array}{l}\text { Li, S.; XU, H.; JI, } \\
\text { Y.; CAO, R; } \\
\text { ZHANG, M.; LI, H. }\end{array}$ & $\begin{array}{l}\text { Descrever um sistema que consiste em } \\
\text { uma máquina mestre e uma máquina } \\
\text { escrava. A mestre é piloto automático ou } \\
\text { condução manual, e o escravo segue o } \\
\text { mestre para realizar uma tarefa de } \\
\text { navegação automática. }\end{array}$ & $\begin{array}{l}\text { O sistema de navegação automática adota um método de controle de } \\
\text { volante e consiste em uma unidade de posicionamento, dispositivo de } \\
\text { controle de direção, unidade de comunicação sem fio e dispositivo } \\
\text { terminal do veículo. A unidade de posicionamento é um receptor de } \\
\text { sistema de GPS. O dispositivo de controle de direção inclui uma unidade } \\
\text { de controle de rotação do volante e uma unidade de feedback de detecção } \\
\text { de ângulo de rotação da roda dianteira. A unidade de comunicação sem } \\
\text { fio adota um rádio de transmissão de dados para transferir as } \\
\text { informações entre o mestre e os escravos }\end{array}$ & $\begin{array}{l}\text { Os resultados experimentais mostraram que o desempenho do } \\
\text { sistema é estável, e o escravo pode seguir o mestre de forma } \\
\text { autônoma a uma velocidade do veículo de } 0,8 \mathrm{~m} / \mathrm{s} \text {. Além disso, o } \\
\text { erro médio é de } 6,76 \mathrm{~cm} \text {, o que pode satisfazer os requisitos de } \\
\text { operação. }\end{array}$ \\
\hline $\begin{array}{l}\text { Optimal Criteria For } \\
\text { Durability Test Of } \\
\text { Stepped } \\
\text { Transmissions of } \\
\text { Agricultural } \\
\text { Tractors } \\
\end{array}$ & 2019 & $\begin{array}{l}\text { MATTETTI, } \\
\text { Michele; } \\
\text { MARALDI, Mirko; } \\
\text { SEDONI, Enrico; } \\
\text { MOLARI, } \\
\text { Giovanni. } \\
\end{array}$ & $\begin{array}{l}\text { Proposta de metodologia para analisar } \\
\text { cargas nas transmissões de tratores com } \\
\text { sensores embutidos e um cronograma de } \\
\text { teste ideal. }\end{array}$ & $\begin{array}{l}\text { Os parâmetros operacionais das transmissões de uma frota de } 44 \text { tratores } \\
\text { foram monitorados ao longo de um ano de uso. A partir dos dados } \\
\text { adquiridos, a amplitude e a frequência da carga em cada componente de } \\
\text { transmissão foram calculadas e pseudo-danos sob diferentes modos de } \\
\text { falha foram calculados }\end{array}$ & $\begin{array}{l}\text { A análise mostrou que o cronograma de teste deve ser definido para } \\
\text { maximizar o torque aplicado a cada componente. Além disso, nem } \\
\text { todas as relações de transmissão precisam necessariamente ser } \\
\text { testadas para testar todas as engrenagens da transmissão. }\end{array}$ \\
\hline $\begin{array}{l}\text { The Development Of } \\
\text { Autonomous } \\
\text { Navigation And } \\
\text { Obstacle Avoidance } \\
\text { For A Robotic } \\
\text { Mower Using } \\
\text { Machine Vision } \\
\text { Technique }\end{array}$ & 2019 & $\begin{array}{l}\text { INOUE, Kosuke; } \\
\text { KAIZU, Yutaka; } \\
\text { IGARASHi, Sho; } \\
\text { IMOU, Kenji. }\end{array}$ & $\begin{array}{l}\text { Desenvolvimento de um sistema de } \\
\text { direção autônomo, capaz de evitar } \\
\text { obstáculos e dirigir sem o auxílio de um } \\
\text { sinal GNSS }\end{array}$ & $\begin{array}{l}\text { O sistema usa um sistema de detecção de objetos que é baseado em uma } \\
\text { câmera estéreo e técnica de aprendizado profundo, ou seja, redes neurais } \\
\text { convolucionais, pois podem ser usadas para reconhecer um ambiente e } \\
\text { evitar obstáculos. }\end{array}$ & $\begin{array}{l}\text { A capacidade de direção autônoma do veículo foi avaliada usando } \\
\text { um Sistema Global de Navegação por Satélite (GNSS) cinemático } \\
\text { em tempo real para medir os valores verdadeiros por meio de } \\
\text { experimentos que foram conduzidos na Floresta Tanashi da } \\
\text { Universidade de Tóquio. }\end{array}$ \\
\hline $\begin{array}{l}\text { Unmanned Aerial } \\
\text { Vehicles In }\end{array}$ & 2019 & $\begin{array}{l}\text { KIM, J.; KIM, S.; } \\
\text { JU, C.; SON, H. I. }\end{array}$ & 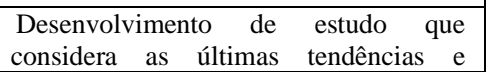 & Discussão do uso de UAVs em ambientes agrícolas reais. & $\begin{array}{l}\text { Apresentação do desenvolvimento futuro dos UAVs agrícolas e } \\
\text { seus desafios. }\end{array}$ \\
\hline
\end{tabular}


Research, Society and Development, v. 10, n. 17, e22101724247, 2021

(CC BY 4.0) | ISSN 2525-3409 | DOI: http://dx.doi.org/10.33448/rsd-v10i17.24247

\begin{tabular}{|c|c|c|c|c|c|}
\hline $\begin{array}{l}\text { Agriculture: A } \\
\text { Review Of } \\
\text { Perspective Of } \\
\text { Platform, Control, } \\
\text { And Application } \\
\end{array}$ & & & $\begin{array}{l}\text { aplicações de tecnologias líderes } \\
\text { relacionadas a UAVs agrícolas, } \\
\text { tecnologias de controle, equipamentos e } \\
\text { desenvolvimento. }\end{array}$ & & \\
\hline $\begin{array}{l}\text { Hardware-In-The- } \\
\text { Loop Test } \\
\text { Automation Of } \\
\text { Embedded Systems } \\
\text { For Agricultural } \\
\text { Tractors } \\
\end{array}$ & 2019 & $\begin{array}{l}\text { RAIKWAR, } \\
\text { Satyam; WANi, L. } \\
\text { Jijyabhau; KUMAR, } \\
\text { S. Arun; RAO, M. } \\
\text { Sreenivasulu. }\end{array}$ & $\begin{array}{l}\text { Discutir em detalhes sobre a facilidade } \\
\text { de automação de testes de Hardware-in- } \\
\text { the-Loop (HIL) usando o hardware da } \\
\text { National Instruments e o software NI } \\
\text { VeriStand }{ }^{\mathrm{TM}} \text { como plataforma de teste. }\end{array}$ & $\begin{array}{l}\text { Esta instalação de teste realiza a execução de teste automático e } \\
\text { verificação de funcionalidade em nível de hardware. Um modelo de } \\
\text { planta foi importado e executado no simulador HII junto com o software } \\
\text { de controle no sistema embarcado para verificação da funcionalidade do } \\
\text { sistema em tempo real. }\end{array}$ & $\begin{array}{l}\text { Adaptando esta metodologia, um tempo considerável foi reduzido } \\
\text { em relação ao teste manual. Esta automação de teste ajuda muito na } \\
\text { redução do tempo de execução do caso de teste, reexecutando o teste } \\
\text { durante a correção de erros do sistema (correção de bug) e para o } \\
\text { teste rápido de protótipo. }\end{array}$ \\
\hline $\begin{array}{l}\text { Application Of A 3D } \\
\text { Tractor-Driving } \\
\text { Simulator For Slip } \\
\text { Estimation-Based } \\
\text { Path-Tracking } \\
\text { Control Of Auto- } \\
\text { Guided Tillage } \\
\text { Operation }\end{array}$ & 2019 & $\begin{array}{l}\text { HAN ,Xiongzhe; } \\
\text { KIM ,Hak-Jin; } \\
\text { JEON, Chan Woo; } \\
\text { MOON, Hee Chang; } \\
\text { KIM, Jung Hun; YI, } \\
\text { Sang Yup. }\end{array}$ & $\begin{array}{l}\text { Estudo de simulação, conduzido usando } \\
\text { um simulador de computador } 3 \mathrm{D} \text {, que } \\
\text { considera o movimento escorregadio de } \\
\text { um trator virtual no solo com } \\
\text { propriedades de aderência variáveis. }\end{array}$ & $\begin{array}{l}\text { A plataforma de teste foi construída com um trator de } 60 \mathrm{~kW} \text { equipado } \\
\text { com um sistema RTK-GPS (sistema de posicionamento cinemático- } \\
\text { global em tempo real) e IMU (unidade de medida inercial), um } \\
\text { controlador de navegação que poderia estimar as derrapagens do trator } \\
\text { em real. Tempo, e um dinamômetro de engate de três pontos que pode } \\
\text { medir as correntes de ar. }\end{array}$ & $\begin{array}{l}\text { Os resultados da simulação de computador confirmaram que o } \\
\text { algoritmo de rastreamento de caminho baseado na estimativa de } \\
\text { deslizamento foi superior em guiar o trator ao longo de caminhos } \\
\text { curvos no solo com coeficientes de rigidez em curva relativamente } \\
\text { baixos. O trator de lavoura autônomo equipado com o algoritmo de } \\
\text { observador de deslizamento demonstrou desempenho aprimorado } \\
\text { em comparação com o sistema desenvolvido anteriormente, } \\
\text { reduzindo o RMSE (erro quadrático médio) para desvio lateral em } \\
\text { caminhos curvos de } 29 \mathrm{~cm} \text { a } 15 \mathrm{~cm} \text {. }\end{array}$ \\
\hline $\begin{array}{l}\text { Automatic Tractor } \\
\text { Slip-Draft Embedded } \\
\text { Control System }\end{array}$ & 2019 & $\begin{array}{l}\text { GUPTA, Chanchal; } \\
\text { TEWARI, V.K.; } \\
\text { KUMAR, A. Ashok; } \\
\text { SHRIVASTAVA, } \\
\text { Prateek. }\end{array}$ & $\begin{array}{l}\text { Projeto, desenvolvimento e teste de um } \\
\text { sistema integrado baseado em } \\
\text { microcontrolador para controle } \\
\text { automático de tração para um trator } \\
\text { 2WD. }\end{array}$ & $\begin{array}{l}\text { O sistema mede e controla de forma síncrona a patinagem da roda e o } \\
\text { calado do implemento mais próximo das faixas definidas em condições } \\
\text { de campo variáveis. As velocidades reais e teóricas foram adquiridas } \\
\text { digitalmente por meio da combinação controlador-efeito Hall empregada } \\
\text { nas rodas dianteiras e traseiras para o acesso digital da patinagem das } \\
\text { rodas. }\end{array}$ & $\begin{array}{l}\text { Observou-se uma variação de escorregamento máximo de } 2 \% \text { entre } \\
\text { os valores calculados e indicados no sistema desenvolvido. O novo } \\
\text { sistema inteligente de controle de tiragem deslizante também } \\
\text { melhorou o desempenho de tração em } 9,17 \% \text { e } 6,05 \% \text { durante a } \\
\text { aração e gradagem, respectivamente, quando analisado em } \\
\text { comparação com um sistema de controle de tiragem existente. }\end{array}$ \\
\hline $\begin{array}{l}\text { A Collaborative } \\
\text { Control Protocol For } \\
\text { Agricultural Robot } \\
\text { Routing With Online } \\
\text { Adaptation }\end{array}$ & 2019 & $\begin{array}{l}\text { DUSADEERUNGSI } \\
\text { KUL, Puwadol Oak; } \\
\text { NOF, Shimon Y. }\end{array}$ & $\begin{array}{l}\text { Utilizar a Teoria do Controle } \\
\text { Colaborativo para construir um novo } \\
\text { sistema, ARS (sistema robótico agrícola) } \\
\text { que sincroniza humanos, um robô móvel } \\
\text { e um conjunto variável de sensores para } \\
\text { realizar de forma eficaz as tarefas de } \\
\text { monitoramento e detecção. }\end{array}$ & $\begin{array}{l}\text { Ao usar a estufa como uma estrutura de estudo de caso, o protocolo } \\
\text { direciona um robô para visitar os locais amostrados usando um algoritmo } \\
\text { genético. Além disso, o algoritmo de busca pode ser guiado pelas } \\
\text { características preditivas do estresse das culturas, que pode se espalhar } \\
\text { para outras plantas de acordo com a luz do sol, a direção do fluxo de ar } \\
\text { e outras condições conhecidas. }\end{array}$ & $\begin{array}{l}\text { Os resultados indicam com significância estatística que (1) o } \\
\text { algoritmo de roteamento aumenta o número de detecções bem- } \\
\text { sucedidas de plantas estressadas existentes em } 45,77 \% \text { em } \\
\text { comparação com o monitoramento sem este algoritmo de } \\
\text { roteamento. (2) O algoritmo de busca adaptativa melhora o número } \\
\text { de detecções bem-sucedidas de plantas estressadas em } 71,88 \% \text { em } \\
\text { comparação com um sistema sem o algoritmo de busca adaptativa. }\end{array}$ \\
\hline $\begin{array}{l}\text { A Practical Effort } \\
\text { To Equip Tractor- } \\
\text { Implement With } \\
\text { Fuzzy Depth And } \\
\text { Draft Control System }\end{array}$ & 2019 & $\begin{array}{l}\text { SHAFAEI, S.M.; } \\
\text { LOGHAVI, M.; } \\
\text { KAMGAR, S. }\end{array}$ & $\begin{array}{l}\text { Pesquisa aplicada estabelecida em } \\
\text { resposta à solicitação do agricultor para } \\
\text { melhorar o desempenho do implemento } \\
\text { trator em operações de cultivo, diminuir } \\
\text { as variações na profundidade de aração, } \\
\text { bem como aumentar a eficiência de } \\
\text { tração de um trator de potência moderada } \\
\text { em operações de preparo do solo com } \\
\text { implementos montados. }\end{array}$ & $\begin{array}{l}\text { O sistema de controle fuzzy consistia em uma unidade de detecção } \\
\text { elétrica, controle e atuador eletro-hidráulico. Um conjunto de comandos } \\
\text { incluindo quatro regras difusas foi programado para a unidade de } \\
\text { controle. Para determinar os méritos do sistema de controle difuso, os } \\
\text { experimentos de campo foram realizados em três níveis de profundidade } \\
\text { de aração }(10,20 \text { e } 30 \mathrm{~cm}) \text {, velocidade de avanço }(2,4 \text { e } 6 \mathrm{~km} / \mathrm{h} \text { ) e tipos } \\
\text { de implementos (arado de aiveca, disco e escarificador) utilizando } \\
\text { sistema montado em trator (MF-399). }\end{array}$ & $\begin{array}{l}\text { A aplicação do sistema de controle difuso em vez do sistema de } \\
\text { controle de tração disponível do trator resultou em incremento da } \\
\text { eficiência de tração e eficiência energética geral em até } 20 \text { e } 73 \% \text {, } \\
\text { respectivamente. Enquanto isso, o erro de profundidade de aragem, } \\
\text { a patinagem da roda motriz e o consumo de combustível diminuíram } \\
\text { para } 53,34 \text { e } 34 \% \text {, respectivamente. }\end{array}$ \\
\hline $\begin{array}{l}\text { Benchmark Of An } \\
\text { Intelligent Fuzzy } \\
\text { Calculator For } \\
\text { Admissible } \\
\text { Estimation Of }\end{array}$ & 2020 & $\begin{array}{l}\text { SHAFAEI, S.M.; } \\
\text { LOGHAVI, M.; } \\
\text { KAMGAR, S. }\end{array}$ & $\begin{array}{l}\text { Proposta de uma calculadora para } \\
\text { estimar a tração da barra de tração } \\
\text { fornecida por um trator mecânico de } \\
\text { tração dianteira. }\end{array}$ & $\begin{array}{l}\text { Com base na variável de entrada nominal do modo de condução do trator } \\
\text { em tração nas duas rodas (2WD) e tração nas quatro rodas }(4 \mathrm{WD}) \text {, e } \\
\text { variáveis de entrada numérica do peso do trator }(53,04-78,45 \mathrm{kN}) \text { e } \\
\text { patinagem das rodas motrizes }(1,4-15,1 \%) \text { utilizando sistemas fuzzy } \\
\text { inteligentes. }\end{array}$ & $\begin{array}{l}\text { Os dados obtidos na calculadora revelaram uma tendência não } \\
\text { linear crescente da tração da barra de tração na faixa de } 12,9-57,5 \\
\mathrm{kN} \text { como aumento simultâneo do deslizamento das rodas e do peso } \\
\text { do trator, para o modo } 2 \mathrm{WD} \text {. No caso do modo } 4 \mathrm{WD} \text {, aumentou de } \\
\text { forma não linear de } 12,8 \text { para } 77,7 \mathrm{kN} \text {. Além disso, as faixas de }\end{array}$ \\
\hline
\end{tabular}


Research, Society and Development, v. 10, n. 17, e22101724247, 2021

(CC BY 4.0) | ISSN 2525-3409 | DOI: http://dx.doi.org/10.33448/rsd-v10i17.24247

\begin{tabular}{|c|c|c|c|c|c|}
\hline $\begin{array}{c}\text { Drawbar Pull } \\
\text { Supplied By } \\
\text { Mechanical Front } \\
\text { Wheel Drive Tractor } \\
\end{array}$ & & & & & $\begin{array}{l}\text { tração da barra de tração elucidaram que a tração da barra de tração } \\
\text { proliferou quando o modo 4WD foi empregado em vez do modo } \\
2 \text { WD. }\end{array}$ \\
\hline $\begin{array}{l}\text { Design Of A Control } \\
\text { System For A Mini- } \\
\text { Automatic } \\
\text { Transplanting } \\
\text { Machine Of Plug } \\
\text { Seedling }\end{array}$ & 2020 & $\begin{array}{l}\text { YANG, Qizhi; } \\
\text { HUANG, Guanlong; } \\
\text { SHI, Xinyi; HE; } \\
\text { Mingsheng; } \\
\text { AHMAD, Ibrar; } \\
\text { ZHAO, Xiaoqi; } \\
\text { ADDY, M. } \\
\end{array}$ & $\begin{array}{l}\text { Projeto de uma máquina para plantio } \\
\text { automático de mudas. }\end{array}$ & $\begin{array}{l}\text { Por meio de uma máquina composta por um conjunto de sensores, } \\
\text { motores elétricos para o posicionamento, um pistão pneumático e um } \\
\text { CPL para controle, o sistema é capaz de realizar o plantio e a extração } \\
\text { das mudas nas bandejas de produção de mudas. }\end{array}$ & $\begin{array}{l}\text { O sistema foi testado para as velocidades de plantio de } 40,50 \text { e } 60 \\
\text { mudas / min tendo alcançado sucesso de } 98,6 \%, 97,2 \% \text { e } 96,5 \% \text {, } \\
\text { respectivamente. }\end{array}$ \\
\hline $\begin{array}{l}\text { Tractor Assistant } \\
\text { Driving Control } \\
\text { Method Based On } \\
\text { EEG Combined With } \\
\text { RNN-TL Deep } \\
\text { Learning Algorithm }\end{array}$ & 2020 & $\begin{array}{l}\text { LU, W.; WEI, Y.; } \\
\text { YUAN, J.; DENG, } \\
\text { Y.; SONG, A. }\end{array}$ & $\begin{array}{l}\text { Método de controle de direção do } \\
\text { assistente de trator baseado na interface } \\
\text { homem-máquina utilizando o sinal } \\
\text { eletroencefalográfico (EEG) para reduzir } \\
\text { operações manuais. }\end{array}$ & $\begin{array}{l}\text { Os sinais de EEG dos motoristas de trator foram coletados por uma } \\
\text { interface cérebro-computador de baixo custo (BCI), seguido por } \\
\text { denoising usando um pacote wavelet. Em seguida, as características } \\
\text { espectrais dos sinais de EEG foram calculadas e extraídas como entrada } \\
\text { da Rede Neural Recorrente (RNN). Além disso, } 8 \text { eletrodos foram } \\
\text { selecionados pelo algoritmo PCA para o projeto de um controlador de } \\
\text { EEG portátil. }\end{array}$ & $\begin{array}{l}\text { Operações de direção reta, freio, curva à esquerda e curva à direita, } \\
\text { cuja precisão de controle foi de } 94,5 \% \text { e o custo de tempo foi de } 0,61 \\
\text { ms. Para resolver o conjunto de dados de direção incompletos no } \\
\text { mundo real porque algumas maneiras de dirigir podem causar perigo } \\
\text { ou até morte, o algoritmo RNN-TL foi empregado criando os dados } \\
\text { de direção completos no ambiente virtual seguido pela transferência } \\
\text { da experiência de controle de direção para o mundo real com } \\
\text { pequeno conjunto de dados reais de condução em campo, cuja } \\
\text { precisão de controle foi de } 93,5 \% \text { e o consumo de tempo foi de } 0,48 \\
\text { ms. }\end{array}$ \\
\hline $\begin{array}{l}\text { Evaluation Of Soil } \\
\text { EC Mapping Driven } \\
\text { By Manual And } \\
\text { Autopilot-Automated } \\
\text { Steering Systems Of } \\
\text { Tractor On Oil Palm } \\
\text { Plantation Terrain } \\
\end{array}$ & 2020 & $\begin{array}{l}\text { AZMI, M.A.; } \\
\text { MOHAMMAD, R.; } \\
\text { PEBRIAN, D.E. }\end{array}$ & $\begin{array}{l}\text { Avaliar a precisão das operações de } \\
\text { trator com implemento de sensor de solo } \\
\text { usando sistemas de direção manuais e } \\
\text { automáticos por piloto automático em } \\
\text { terrenos de plantação de dendê na } \\
\text { Malásia. }\end{array}$ & $\begin{array}{l}\text { Um trator New Holland TD } 5.75 \text { com motor de } 75 \text { hp equipado com um } \\
\text { sistema de direção automatizado de piloto automático Trimble puxando } \\
\text { um sensor de condutividade elétrica do solo (EC) Veris } 3100 \text { foi testado } \\
\text { neste estudo. }\end{array}$ & $\begin{array}{l}\text { Os resultados mostraram que cada sistema de direção gerou um } \\
\text { padrão um pouco diferente de variabilidade espacial em mapas CE } \\
\text { de solo interpolados. Além disso, o sistema de direção automatizado } \\
\text { por piloto automático ofereceu melhores desempenhos, } \\
\text { economizando o gasto de energia do operador e melhorando a } \\
\text { capacidade de operação em campo. }\end{array}$ \\
\hline $\begin{array}{l}\text { Outlining The } \\
\text { Mission Profile Of } \\
\text { Agricultural } \\
\text { Tractors Through } \\
\text { CAN-BUS Data } \\
\text { Analytics } \\
\end{array}$ & 2021 & $\begin{array}{l}\text { MATTETTI, M.; } \\
\text { MARALDI, M.; } \\
\text { LENZINI, N.; } \\
\text { FIORATI, S.; } \\
\text { SERENI. E.; } \\
\text { MOLARI, G. } \\
\end{array}$ & $\begin{array}{l}\text { Apresentar um novo esquema de } \\
\text { classificação de dados CAN-BUS de } \\
\text { protocolo ISO } 11.783 \text { que permite } \\
\text { delinear a utilização do trator }\end{array}$ & $\begin{array}{l}\text { Em um trator, um registrador de dados CAN-BUS foi instalado e um } \\
\text { receptor GNSS, e os dados foram registrados por } 579 \text { horas de operação } \\
\text { determinando condições reais de trabalho. }\end{array}$ & $\begin{array}{l}\text { O método demonstrou ser capaz de detectar } 97 \% \text { dos dados } \\
\text { registrados e que o trator operou no campo em regime de trabalho, } \\
\text { ociosidade e deslocamento em } 65 \%, 18 \% \text { e } 16 \% \text { do tempo, } \\
\text { respectivamente. }\end{array}$ \\
\hline $\begin{array}{l}\text { Farmers' } \\
\text { Perspectives On Field } \\
\text { Crop Robots } \\
\text { Evidence From } \\
\text { Bavaria, Germany }\end{array}$ & 2021 & $\begin{array}{l}\text { SPYKMAN, O.; } \\
\text { GABRIEL, A.; } \\
\text { PTACEK, M.; } \\
\text { GANDORFER, M. }\end{array}$ & $\begin{array}{l}\text { Investigação exploratória dos fatores } \\
\text { que influenciam a preferência por robôs } \\
\text { de lavouras grandes ou pequenas em } \\
\text { geral e em ambientes específicos e pelo } \\
\text { modo de operação com base em uma } \\
\text { amostra de } 174 \text { agricultores. }\end{array}$ & $\begin{array}{l}\text { Os dados foram coletados por meio de questionários em dois eventos, } \\
\text { incluindo palestras e demonstrações de campo, e analisados por meio de } \\
\text { testes bivariados. O tamanho da fazenda, o sistema de cultivo (orgânico } \\
\text { / convencional) e a estrutura ocupacional (meio período / período } \\
\text { integral) foram atributos relevantes que influenciam a avaliação das } \\
\text { vantagens e desvantagens dos robôs de cultivo no campo }\end{array}$ & $\begin{array}{l}\text { Os entrevistados de fazendas maiores se concentram mais nos } \\
\text { benefícios financeiros dos robôs e preferem grandes tratores } \\
\text { autônomos. Por outro lado, os agricultores de pequena escala ou } \\
\text { orgânicos consideram os benefícios ambientais dos robôs de cultivo } \\
\text { relativamente mais importantes e favorecem os robôs pequenos. A } \\
\text { agricultura orgânica também se correlaciona positivamente com a } \\
\text { intenção de comprar robôs de cultivo agrícola nos próximos cinco } \\
\text { anos. Mais agricultores geralmente podem imaginar possuir } \\
\text { pequenos robôs em vez de um trator autônomo em dez anos. }\end{array}$ \\
\hline $\begin{array}{l}\text { Fuzzy Logic Based } \\
\text { Automatic Slip } \\
\text { Control System For } \\
\end{array}$ & 2021 & $\begin{array}{l}\text { SOYLU, Serhat; } \\
\text { ÇARMAN, Kazım. }\end{array}$ & $\begin{array}{l}\text { Desenvolver um sistema de controle } \\
\text { automático de deslizamento baseado em } \\
\text { fuzzy para tratores agrícolas. }\end{array}$ & $\begin{array}{l}\text { O sistema desenvolvido mede continuamente a quantidade de } \\
\text { deslizamento que ocorre durante as atividades de preparo do solo e altera } \\
\text { automaticamente a profundidade de operação do equipamento de } \\
\text { preparo de acordo com o aumento do valor do deslizamento. A }\end{array}$ & $\begin{array}{l}\text { Como resultado dos ensaios, em comparação com o controle do } \\
\text { operador, foi determinado que nas atividades de preparo realizadas } \\
\text { com FCS, houve diminuições de } 42 \% \text { nos valores de } \\
\text { escorregamento, diminuições de } 30 \% \text { nos valores de força de tração, }\end{array}$ \\
\hline
\end{tabular}


Research, Society and Development, v. 10, n. 17, e22101724247, 2021

(CC BY 4.0) | ISSN 2525-3409 | DOI: http://dx.doi.org/10.33448/rsd-v10i17.24247

\begin{tabular}{|c|c|c|c|c|c|}
\hline $\begin{array}{c}\text { Agricultural } \\
\text { Tractors }\end{array}$ & & & & $\begin{array}{l}\text { quantidade de deslizamento que ocorre nas rodas motrizes foi aplicada } \\
\text { como uma entrada separada para o sistema de controle difuso projetado } \\
\text { (FCS) e na base de regra difusa, foi decidido quanto a profundidade do } \\
\text { cultivo seria reduzida. }\end{array}$ & $\begin{array}{l}\text { diminuições de } 44 \% \text { nos valores de consumo de combustível e } \\
\text { aumentos de } 5 \% \text { nos valores de desempenho do trabalho de campo. } \\
\text { Observou-se também que ocorreram alterações de } 10 \% \text { na } \\
\text { profundidade do preparo do solo. }\end{array}$ \\
\hline $\begin{array}{l}\text { Adaptation Of Tilt } \\
\text { Adjustment And } \\
\text { Tracking Force } \\
\text { Automation System } \\
\text { On A Laser- } \\
\text { Controlled Land } \\
\text { Leveling Machine } \\
\end{array}$ & 2021 & $\begin{array}{l}\text { İRSEL, Gürkan M.; } \\
\text { ALTINBALIK, } \\
\text { Tahir. }\end{array}$ & $\begin{array}{l}\text { Analisar trabalhos de mecanização e } \\
\text { automação realizados para melhorar a } \\
\text { eficiência operacional das máquinas de } \\
\text { nivelamento a laser e projetar um sistema } \\
\text { mais preciso, ergonômico, econômico e } \\
\text { confiável. }\end{array}$ & $\begin{array}{l}\text { Este novo design consiste em um sistema de automação de ajuste de } \\
\text { inclinação da lâmina, sistema de automação de esteira e sistema de } \\
\text { proteção de carga máxima. Com seu novo design, a máquina pode } \\
\text { nivelar terrenos mais difíceis por menos número de repetições e menos } \\
\text { consumo de combustível com uma precisão de gradiente de } 0,05^{\circ} \text {. }\end{array}$ & $\begin{array}{l}\text { Após o projeto, a economia de tempo de } 80 \% \text { e a economia de } \\
\text { combustível de } 85 \% \text { foram alcançadas para as superfícies com a } \\
\text { mesma área e aproximadamente } 10^{\prime} \mathrm{L} \text { de economia de combustível } \\
\text { por hectare foi realizada. }\end{array}$ \\
\hline $\begin{array}{l}\text { Modeling and } \\
\text { Motion Control of } \\
\text { Industrial Tractor- } \\
\text { Trailers Vehicles } \\
\text { Using Force } \\
\text { Compensation } \\
\end{array}$ & 2021 & $\begin{array}{l}\text { ZHAO, H.; ZHOU, } \\
\text { S.; CHEN, W.; } \\
\text { MIAO, Z.; LIU, Y. - } \\
\text { H. }\end{array}$ & $\begin{array}{l}\text { Modelagem dinâmica e o controle de } \\
\text { rastreamento de trajetória do veículo } \\
\text { trator-reboques industrial composto por } \\
\text { um trator semelhante a um carro e vários } \\
\text { reboques completos }\end{array}$ & $\begin{array}{l}\text { Para eliminar a grande incerteza dos parâmetros cinemáticos e } \\
\text { dinâmicos dos reboques no modelo, foi proposta a instalação de um } \\
\text { sensor de força para monitorar as forças exercidas no trator em tempo } \\
\text { real. Um controlador de rastreamento de trajetória baseado em Lyapunov } \\
\text { é proposto para compensar on-line as forças e conduzir o trator na } \\
\text { trajetória desejada. O controlador é desenvolvido utilizando técnicas de } \\
\text { backstepping e a estabilidade é rigorosamente comprovada. }\end{array}$ & $\begin{array}{l}\text { Os resultados da implementação mostram que a aplicação do } \\
\text { modelo simplificado geralmente tem um desempenho superior do } \\
\text { que usar o modelo de veículo completo. }\end{array}$ \\
\hline $\begin{array}{c}\text { Identification Of } \\
\text { Tobacco Crop Based } \\
\text { On Machine } \\
\text { Learning For A } \\
\text { Precision } \\
\text { Agricultural Sprayer }\end{array}$ & 2021 & $\begin{array}{l}\text { TUFAIL, M.; } \\
\text { IQBAL, J.; } \\
\text { TIWANA, M. I.; } \\
\text { ALAM, M. S.; } \\
\text { KHAN, Z. A.; } \\
\text { KHAN, M. T. }\end{array}$ & $\begin{array}{l}\text { Apresentar um sistema de detecção de } \\
\text { culturas / ervas daninhas baseado em } \\
\text { aprendizado de máquina para um } \\
\text { pulverizador de barra montado em um } \\
\text { trator que poderia executar a } \\
\text { pulverização específica do local na } \\
\text { cultura do tabaco nos campos }\end{array}$ & $\begin{array}{l}\text { Um classificador SVM com uma combinação de características } \\
\text { cuidadosamente escolhida (textura, forma e cor) para a planta de tabaco } \\
\text { foi proposto e uma precisão de classificação de } 96 \% \text { foi alcançada. O } \\
\text { algoritmo foi treinado e testado em um conjunto de dados real coletado } \\
\text { em campos locais com diversas mudanças em escala, orientação, } \\
\text { desordem de fundo, condições de iluminação externa e variação entre } \\
\text { tabaco e ervas daninhas. A comparação de desempenho do algoritmo } \\
\text { proposto foi feita com um classificador baseado em deep learning } \\
\text { (customizado para inferência em tempo real). }\end{array}$ & $\begin{array}{l}\text { Ambos os algoritmos foram implantados em um pulverizador } \\
\text { montado em trator em campos de tabaco e concluiu-se que o } \\
\text { classificador SVM tem um bom desempenho em termos de precisão } \\
(96 \%) \text { e inferência em tempo real (6 FPS) em um dispositivo } \\
\text { embutido (Raspberry Pi 4). Em comparação, o classificador baseado } \\
\text { em aprendizado profundo personalizado tem uma precisão de } 100 \% \text {, } \\
\text { mas tem um desempenho muito mais lento (0,22 FPS) no Raspberry } \\
\text { Pi } 4 \text {. }\end{array}$ \\
\hline
\end{tabular}

Fonte: Autores (2021). 


\section{Considerações Finais}

Diante da análise dos trabalhos desenvolvidos acerca da utilização da instrumentação em máquinas agrícolas, nota-se que a utilização dos instrumentos é imprescindível na automação dos processos na agricultura já que o aumento da produção agrícola sem aumento das áreas plantadas é o grande desafio do setor.

Os artigos selecionados para RSL descrevem utilização de instrumentos para automação em diversos processos e também para coleta de dados para vários estudos, aliado ao fato da evolução da quantidade de estudos realizados nos anos analisados, conclui-se um processo contínuo de evolução das tecnologias na agricultura e também a importância desse desenvolvimento para a produção agrícola. Notou-se que a automação dos equipamentos utilizados na produção mecanizada da agricultura proporciona aumento da produtividade e/ou redução de tempo de trabalho de máquina, dessa forma possibilitando melhor eficiência dos equipamentos e, portanto, mais produção com menos consumo de combustível por área plantada e deste modo uma produção agrícola mais eficiente.

A RSL realizada, torna-se uma referência pois descreve a tendência dos estudos realizados nos anos determinados pela pesquisa e dessa forma indicando possíveis direções para realização de novos trabalhos tais como: Instrumentação aplicada em motores agrícolas para detecção de contaminantes no sistema de admissão de ar, utilização de sensores para estimar a massa de produto agrícola colhido em equipamentos de transbordo, desenvolvimento de dispositivo para controle de rotação do exaustor primário de colhedoras de cana-de-açúcar, entre outros.

\section{Referências}

AzmI, M. A. Mohammad, R. \& Pebrian, D. E. (2020). Evaluation Of Soil EC Mapping Driven By Manual And Autopilot-Automated Steering Systems Of Tractor On Oil Palm Plantation Terrain, Food Research, 4(5), 62 - 69.

Conforto, E.C. Amaral, D.C. \& Silva, S.L. (2011). Roteiro para revisão bibliográfica sistemática: aplicação no desenvolvimento de produtos e gerenciamento de projeto. In: Congresso Brasileiro De Gestão De Desenvolvimento De Produto - CBGDP, 8, Anais... Porto Alegre, RS.

Dusadeerungsikul, P. O. \& NOF, S. Y. (2019). A collaborative control protocol for agricultural robot routing with online adaptation, Computers Industrial Engineering, 135, 456-466.

Espejo, G. B. Martinez, G. J. Pérez, R. M. Lopez, P. F.J. \& Javier, Z. F. (2018). Machine learning for automatic rule classification of agricultural regulations: a case study in Spain. Comput Electron Agric. 150: 343-352.

Gupta, C. Tewari, V.K. Kumar, A. A. \& Shrivastava, P. (2019). Automatic tractor slip-draft embedded control system, Computers and Electronics in Agriculture, 165 .

Han, X. Kim, H. Jeon, C. W. Moon, H. C. Kim, J. H. \& Yi, S. Y. (2019). Application of a 3D tractor-driving simulator for slip estimation-based path-tracking control of auto-guided tillage operation, Biosystems Engineering, 178, 70-85.

Inoue, K. Kaizu, Y. Igarashi, S. \& Imou, K. (2019). The development of autonomous navigation and obstacle avoidance for a robotic mower using machine vision technique, IFAC-PapersOnLine, 52(30), 173-177.

İrsel, G. M.; \& Altinbalik, T. (2018). Adaptation of tilt adjustment and tracking force automation system on a laser-controlled land leveling machine, Computers and Electronics in Agriculture, 150, 374-386.

Kim, J. Kim, S. Ju, C. \& Son, H. I. (2019). Unmanned Aerial Vehicles in Agriculture: A Review of Perspective of Platform, Control, and Applications, IEEE Access, 7, 105100-105115.

Kim, Y Chung, S., \& Choi, C.H. (2018). Development of automation technology for manual transmission of a 50 HP autonomous tractor. IFAC-PapersOnLine. 51. 20-22.

Kumar, A. A. Tewari, V.K. Nare, B. Chetan, C.R. Srivastava, P. \& Kumar, S. P. (2017). Embedded Digital Drive Wheel Torque Indicator For Agricultural 2WD Tractors. Computers and electronics in agriculture, 139, 91-102.

Lee, J. Kim, H. Cho, B Choi, J., \& Kim, Y. (2018). Road Bump Detection Using LiDAR sensor for Semi-Active Control of Front Axle Suspension in an Agricultural Tractor. IFAC-PapersOnLine. 51, 124-129.

Li, S. Xu, H. Ji, Y. Cao, R Zhang, M. \& Li, H. (2019). Development of a following agricultural machinery automatic navigation system, Comput. Electron. Agricult., 158, 335-344.

Lu, W. Wei, Y. Yuan, J. Deng, Y. \& Song, A. (2020). Tractor Assistant Driving Control Method Based on EEG Combined With RNN-TL Deep Learning Algorithm, IEEE Access, 8, 163269-163279. 
Research, Society and Development, v. 10, n. 17, e22101724247, 2021 (CC BY 4.0) | ISSN 2525-3409 | DOI: http://dx.doi.org/10.33448/rsd-v10i17.24247

Mccool, C. S. Perez, T. \& Upcroft, B. (2017). Mixtures of Lightweight Deep Convolutional Neural Networks: Applied to Agricultural Robotics, IEEE Robotics and Automation Letters. 2, 1344-1351.

Mattetti, M. Molari, G. \& Sereni, E. (2017). Damage Evaluation Of Driving Events For Agricultural Tractors. Computers and Electronics in Agriculture, 135, $328-337$.

Mattetti, M. Maraldi, M. Lenzini, N. Fiorati, S. Sereni. E. \& Molari, G. (2021). Outlining the mission profile of agricultural tractors through CAN-BUS data analytics, Computers and Electronics in Agriculture, 184, 106078.

Mattetti, M Maraldi, M Sedoni, E., \& Molari, G. (2019). Optimal criteria for durability test of stepped transmissions of agricultural tractors, Biosystems Engineering, 178, 145-155.

ONU. (2021). Objetivos de Desenvolvimento Sustentável (ODS), Pacto Global, Disponível em: https://www.pactoglobal.org.br/ods.

Pasternak, G. Greenman, J. \& Ieropoulos, I. (2017). Self-Powered, Autonomous Biological Oxygen Demand Biosensor For Online Water Quality Monitoring. Sensors Actuators B Chemical. 244, 815-822.

Perz, R. \& Wronowski, K. (2018). UAV application for precision agriculture, Aircraft Engineering and Aerospace Technology, 91, $257-263$.

Rajabi-Vandechali, M. Abbaspour-Fard, M. \& Rohani, A. (2018). Development of a prediction model for estimating tractor engine torque based on soft computing and low cost sensors. Measurement. 121, 83-95.

Rajkumar, S. Arun M. Hirwani, J. \& Sanjeev, S. (2018). Predictive analysis of crops cultivation for a smart green environment using azure services. International Journal of Recent Technology and Engineering (IJRTE). 7, 295-298.

Raikwar, S. Wani, L. J. Kumar, S. A. \& Rao, M. S. (2019). Hardware-in-the-Loop test automation of embedded systems for agricultural tractors, Measurement, $133,271-280$.

Ranjbarian, S.; Askari, M.; \& Jannatkhah, J. (2017) Performance of tractor and tillage implements in clay soil. Journal of the Saudi Society of Agricultural Sciences, 16(2), 154-162.

Shafaei, S.M. Loghavi, M. \& Kamgar, S. (2019). A practical effort to equip tractor-implement with fuzzy depth and draft control system, Engineering in Agriculture, Environment and Food, 12(2), 191-203.

Shafaei, S.M. Loghavi, M. \& Kamgar, S. (2020). Benchmark of an intelligent fuzzy calculator for admissible estimation of drawbar pull supplied by mechanical front wheel drive tractor, Artificial Intelligence in Agriculture, 4, 209-218.

Soylu, S. Çarman, K. (2021). Fuzzy logic based automatic slip control system for agricultural tractors, Journal of Terramechanics, 95 , $25-32$.

Spykman, O. Gabriel, A. Ptacek, M. \& Gandorfer, M. (2021). Farmers' perspectives on field crop robots - Evidence from Bavaria, Germany, Computers and Electronics in Agriculture, 186, 106176.

Sulistyo, S.B. Wu, D. Woo, W.L. Dlay, S. S. \& Gao, B. (2017). Computational Deep Intelligence Vision Sensing For Nutrient Content Estimation In Agricultural Automation. IEEE Transactions on Automation Science and Engineering, 15, 1243-1257.

Tufail, M. Iqbal, J. Tiwana, M. I. Alam, M. S. Khan, Z. A. \& Khan, M. T. (2021) Identification of Tobacco Crop Based on Machine Learning for a Precision Agricultural Sprayer, IEEE Access, 9, 23814-23825.

Yalei, W. Lijun, Q. \& Hao, Z. (2018). Design and experiment of remote intelligent spray control system based on embedded internet. Trans. Chin. Soc. Agric. Eng. 34(20), 28-35.

Yang, Q. Huang, G. Shi, X. He, M. Ahmad, I. Zhao, X. \& Addy, M. (2020) Design of a control system for a mini-automatic transplanting machine of plug seedling, Computers and Electronics in Agriculture, 169.

Zhang, S. Wang, Y. Zhu, Z. Li, Z. Du, Y. \& Mao, E. (2018). Tractor Path Tracking Control Based on Binocular Vision. Information Processing in Agriculture, $5,422-432$.

Zhao, H. Zhou, S. Chen, W. Miao, Z. \& Liu, Y. H. (2021). Modeling and Motion Control of Industrial Tractor-Trailers Vehicles Using Force Compensation, IEEE/ASME Transactions on Mechatronics, 26(2), 645-656. 